\title{
THE ROLE OF MOTIVATION IN THE LANGUAGE TEACHING CLASSROOM
}

\author{
Nazakat Mammadova, Azerbaijan State Oil and Industry University, Azerbaijan
}

DOI: https://doi.org/10.31435/rsglobal_conf/25032021/7466

\begin{abstract}
Motivation refers to the forces that cause people to behave in certain ways. The students who spend the weekend in the library and the students who cannot wait to get out of class to go to the beach are both motivated, but they have different goals and interests. Of course, motivation is not the only factor in student performance. To perform well, a student must also have the right abilities and resources. Without motivation, however, even the most capable working student with excellent support will accomplish little. Problem Statement Students in today's high schools feel disconnected from subject matter and the benefits of learning.
\end{abstract}

Keywords: motivation, classroom, encourage, materials, purpose, importance.

Introduction. Motivation and engagement are difficult to achieve in any classroom. Why do some people seem to be successful and driven while others seem to have trouble making themselves get out of bed in the morning? Where does that energy, direction or motivation come from? Motivation has been a topic of study for many generations and the reason is all people want to be successful. Establishment of classroom conditions in which students are motivated to learn academic course content continues to be an important but elusive goal of educators. Teachers and administrators from all academic disciplines are continually perplexed by some students' limited efforts in the classroom. Why is this student not motivated to learn? What can be done to cause this student to want to know more?

While teachers seek answers, educational researchers provide few concrete solutions. In fact, despite its recognized importance, motivation continues to play a 1 curious role in instructional literature. While many studies ignore the concept altogether, others view student motivation as just another independent variable: a personality attribute over which educators have little influence. Motivation to learn in the classroom is rarely examined as a dependent measure: a factor which may be influenced in order to enhance learning. As a result, the knowledge of creating and sustaining student interest in learning pales in comparison to the knowledge of facilitating learning once the student wants to learn.

The importance of motivation. Motivation in the classroom is an important aspect of the educational environment. Children who are not motivated are generally poor learners, and to some extent, have behavioral problems. Motivation will be difficult to achieve in students without some history of success in their efforts at learning. Intrinsic motivation, which is necessary for the child to become a lifelong learner, will be impossible to accomplish.

Another area that is related to motivation is the training of students to accept delayed gratification. Again, this is accomplished by instilling intrinsic motivation in the student. The teacher must transfer desire for concrete rewards to internal rewards that the student builds within his or her cognitive process. But this cannot be accomplished until the child is cognitively ready to think in such terms.

Students who are not academically prepared are not academically motivated. Of course, because of ethical concerns it would be difficult to examine this relationship in a format that would suggest a causal connection. However, it seems only logical that if a child were not cognitively prepared to learn a skill or understand a concept because of his or her stage of cognitive child development, this would impact the student's motivation and the teacher's ability to effectively build intrinsic motivation within the child's learning process. Consequently, in order for the teacher to accomplish the goals of motivation and skill building, it would appear to necessary for the primary strategy within the classroom to be one determining the child's cognitive level or readiness before teaching a task. If the task is beyond the stage or capability of the child, then he or she will experience failure, which will reduce his or her level of motivation.

Virtually all students are motivated in one way or another. One student may be keenly interested in classroom subject matter and seek out challenging course work, participate actively in class discussions, and earn high marks on assigned projects. Another student may be more concerned with the social side of school, interacting with classmates frequently, attending extracurricular activities almost every day, and perhaps running for a student government office. Still another may be 
focused on athletics, excelling in physical education classes, playing or watching sports most afternoons and weekends, and faithfully following a physical fitness regimen. Yet another student perhaps because of an undetected learning disability, a shy temperament, or a seemingly uncoordinated body - may be motivated to avoid academics, social situations, or athletic activities.

Significance and purpose of problem. As a teacher, I know it is hard to motivate students to learn. Many of my students are struggling with abuse, gang violence or caring for their own children. It is harder still to motivate students to learn material they do not believe will help them with future goals. The sciences are misunderstood by students today as a non-essential part of their future. The truth is that science is the driving force of modem culture. In today's world of high tech, high-speed communications, it is more critical than ever before for teachers to hook and hold students' interest in science, mathematics and technology.

The purpose of this paper is to increase my own knowledge of motivational factors specific for my students and to share this information with my colleagues. In this paper, I will investigate the research regarding student motivation, particularly pertaining to the use of technology in the classroom. It is my intention to not only use technology to present material to the students, but to also involve students in the use of technology for research, investigations and presenting what they have learned.

Teachers know that encouraging student interest and motivation for school related learning activities is a complex task. Part of this complexity comes from the fact that students may have multiple goals or many and varied reasons for studying. The individual goals that are strived for through learning and achieving in school can be situated on two dimensions: intrinsic versus extrinsic goals and immediate versus future goals. In many places, student academic achievement is poor and behavior even worse. They see little point in academic achievement and science is a course for which they do not see a practical purpose.

Types of motivation in classroom. Intrinsic motivators include fascination with the subject, a sense of its relevance to life and the world, a sense of accomplishment in mastering it, and a sense of calling to it.

Advantages. Intrinsic motivation can be long-lasting and self-sustaining. Efforts to build this kind of motivation are also typically efforts at promoting student learning. Such efforts often focus on the subject rather than rewards or punishments.

Disadvantages. On the other hand, efforts at fostering intrinsic motivation can be slow to affect behavior and can require special and lengthy preparation. Students are individuals, so a variety of approaches may be needed to motivate different students. It is often helpful to know what interests one's students in order to connect these interests with the subject matter. This requires getting to know one's students.

Extrinsic motivators include parental expectations, expectations of other trusted role models, earning potential of a course of study, and grades (which keep scholarships coming).

Advantages. Extrinsic motivators more readily produce behavior changes and typically involve relatively little effort or preparation. Also, efforts at applying extrinsic motivators often do not require extensive knowledge of individual students.

Disadvantages. On the other hand, extrinsic motivators can often distract students from learning the subject at hand. It can be challenging to devise appropriate rewards and punishments for student behaviors. Often, one needs to escalate the rewards and punishments over time to maintain a certain effect level. Also, extrinsic motivators typically do not work over the long term. Once the rewards or punishments are removed, students lose their motivation.

Effects of motivation on learning styles. Deep learners respond well to the challenge of mastering a difficult and complex subject. These are intrinsically motivated students who are often a joy to teach.

- Strategic learners are motivated primarily by rewards. They react well to competition and the opportunity to best others. They often make good grades but won't engage deeply with a subject unless there is a clear reward for doing so. They are sometimes called "bulimic learners," learning as much as they need to do well on a test or exam and then promptly forgetting the material once the assessment is over. Handle strategic learners by avoiding appeals to competition. Appeal to their intrinsic interest in the subject at hand. Design your assignments (tests, papers, projects, etc.) so that deep engagement with the subject is necessary for success on the assignments. Do so by requiring students to apply, synthesize, or evaluate material instead of merely comprehending or memorizing material. 
- Surface learners are often motivated by a desire to avoid failure. They typically avoid deep learning because it they see it as inherently risky behavior. They will often do what it takes to pass an exam or course, but they won't choose to go beyond the minimum required for fear of failure. Handle surface learners by helping them gain confidence in their abilities to learn and perform. "Scaffold" course material and assignments by designing a series of activities or assignments that build on each other over time in complexity and challenge. Encourage these learners often and help them reflect on what they've learned and what they've accomplished.

Motivation has several effects on students' learning and behavior.

- Motivation directs behavior toward particular goals. Social cognitive theorists propose that individuals set goals for themselves and direct their behavior accordingly. Motivation determines the specific goals toward which learners strive. Thus, it affects the choices students make-for instance, whether to enroll in physics or studio art, whether to spend an evening completing a challenging homework assignment or playing videogames with friends.

- Motivation leads to increased effort and energy. Motivation increases the amount of effort and energy that learners expend in activities directly related to their needs and goals. It determines whether they pursue a task enthusiastically and wholeheartedly or apathetically and lackadaisically.

- Motivation increases initiation of and persistence in activities. Learners are more likely to begin a task they actually want to do. They are also more likely to continue working at it until they've completed it, even if they are occasionally interrupted or frustrated in the process. In general, then, motivation increases students' time on task, an important factor affecting their learning and achievement.

- Motivation affects cognitive processes. Motivation affects what learners pay attention to and how effectively they process it. For instance, motivated learners often make a concerted effort to truly understand classroom material - to learn it meaningfully - and consider how they might use it in their own lives.

- Motivation determines which consequences are reinforcing and punishing. The more learners are motivated to achieve academic success, the more they will be proud of an A and upset by a low grade. The more learners want to be accepted and respected by peers, the more they will value membership in the "in" group and be distressed by the ridicule of classmates. To a teenage boy uninterested in athletics, making or not making the school football team is no big deal, but to a teen whose life revolves around football, making or not making the team may be a consequence of monumental importance.

- Motivation often enhances performance. Because of the other effects just identified - goaldirected behavior, effort and energy, initiation and persistence, cognitive processing, and the impact of consequences - motivation often leads to improved performance. As you might guess, then, students who are most motivated to learn and excel in classroom activities tend to be our highest achievers. Conversely, students who have little interest in academic achievement are at high risk for dropping out before they graduate from high school.

Strategies for motivating students.

- Become a role model for student interest. Deliver your presentations with energy and enthusiasm. As a display of your motivation, your passion motivates your students. Make the course personal, showing why you are interested in the material.

- Get to know your students. You will be able to better tailor your instruction to the students' concerns and backgrounds, and your personal interest in them will inspire their personal loyalty to you. Display a strong interest in students' learning and a faith in their abilities.

- Use examples freely. Many students want to be shown why a concept or technique is useful before they want to study it further. Inform students about how your course prepares students for future opportunities.

- Use a variety of student-active teaching activities. These activities directly engage students in the material and give them opportunities to achieve a level of mastery.

- Teach by discovery. Students find as satisfying as reasoning through a problem and discovering the underlying principle on their own. pressure.

- Cooperative learning activities are particularly effective as they also provide positive social

- Set realistic performance goals and help students achieve them by encouraging them to set their own reasonable goals. Design assignments that are appropriately challenging in view of the experience and aptitude of the class. 
- Place appropriate emphasis on testing and grading. Tests should be a means of showing what students have mastered, not what they have not. Avoid grading on the curve and give everyone the opportunity to achieve the highest standard and grades.

- Be free with praise and constructive in criticism. Negative comments should pertain to particular performances, not the performer. Offer nonjudgmental feedback on students' work, stress opportunities to improve, look for ways to stimulate advancement, and avoid dividing students into sheep and goats.

- Give students as much control over their own education as possible. Let students choose paper and project topics that interest them. Assess them in a variety of ways (tests, papers, projects, presentations, etc.) to give students more control over how they show their understanding to you.

Conclusions. The best lessons, books, and materials in the world won't get students excited about learning and willing to work hard if they're not motivated. Motivation is a key factor in the success of students at all stages of their education, and teachers can play a pivotal role in providing and encouraging that motivation in their students. Of course, that's much easier said than done, as all students are motivated differently and it takes time and a lot of effort to learn to get a classroom full of kids enthusiastic about learning, working hard, and pushing themselves to excel.

Even the best intentioned and educated teachers sometimes lack the skills to keep kids on track, so whether you're a new teacher or an experienced one, try using these methods to motivate your students and to encourage them to live up to their true potential.

\section{REFERENCES}

1. Bennett, J. (2003). Teaching and learning science: A guide to recent research and its applications. London: Continuum.

2. Broussard, C. (2002). The relationship between classroom motivation and academic achievement in first and third grades. Master thesis, Louisiana State University.

3. Bruner, J. (1996). The culture of education. Cambridge, MA: Harvard University Press.

4. Ken Bain, What the Best College Teachers Do, Harvard University Press, 2004, pages 32-42.

5. Linda Nilson, Teaching at Its Best: A Research-Based Resource for College Instructors, 2nd edition, Anker Publishing, 2003, pages 41-44.

6. Source: Ken Bain, What the Best College Teachers Do, Harvard University Press, 2004, pages 32-33. 